\title{
ANÁLISE MICROFACIOLÓGICA DE UMA SEÇÃO EM TESTEMUNHO DA FORMAÇÃO COTINGUIBA, CRETÁCEO DA BACIA DE SERGIPE- ALAGOAS
}

\author{
MICROFACIES ANALYSIS OF A WELL CORE SECTION FROM THE COTINGUIBA \\ FORMATION, CRETACEOUS OF SERGIPE-ALAGOAS BASIN
}

\author{
Rodrigo Soares Monteiro da SILVA ${ }^{1}$, Júlia FAVORETO²; Jane Nobre LOPES ${ }^{2}$, Leonardo \\ BORGHI ${ }^{2}$ \\ ${ }^{1}$ Centro de Informações da Produção de Petróleo e Gás Natural (CIPEG) - Departamento de Recursos Minerais do Rio de Janeiro. \\ Rua Marechal Deodoro 351, Niterói - RJ. monteiro.geologia@gmail.com \\ ${ }^{2}$ Universidade Federal do Rio de Janeiro- Laboratório de Geologia Sedimentar. Avenida Athos da Silveira Ramos 274. Cidade \\ Universitária - Ilha do Fundão. Rio de Janeiro - RJ. julia@geologia.ufrj.br; janenobre@gmail.com; lborghi@geologia.ufrj.br
}

\author{
Introdução \\ Materiais e métodos \\ Contexto geológico \\ Resultados \\ Discussões \\ Conclusões \\ Agradecimentos \\ Referências bibliográficas
}

\begin{abstract}
RESUMO - Na transição Cenomaniano-Turoniano registra-se mundialmente o maior evento de subida do nível eustático do Cretáceo. Insere-se nesse contexto a Formação Cotinguiba (Bacia de Sergipe-Alagoas), que resulta da transgressão responsável pela construção de uma rampa carbonática com talude distal, durante o afogamento do sistema plataformal sotoposto (até meados do Coniaciano). Essas unidades de grã fina distais constituem análogos aflorantes de potenciais rochas-selante das bacias da margem continental sudeste (e.g., Formação Outeiro, Bacia de Campos), o que torna sua análise faciológica importante para a caracterização tecnológica de sistemas petrolíferos em que participem. Logo, este estudo objetiva caracterizar microfaciologicamente uma seção de $100 \mathrm{~m}$ de extensão, em testemunho de sondagem da Formação Cotinguiba, associadamente ao contexto estratigráfico, a fim de: definir os atributos sedimentológicos diagnósticos da sua situação paleoambiental; e avaliar a evolução paleoambiental, registrada pela sucessão microfaciológica assim estabelecida. Para tanto, foi elaborado um perfil sedimentológico da referida seção, ao qual a análise petrográfica complementar atribuiu onze microfácies (definidas por critérios composicionais, texturais e paleontológicos). Estudos bioestratigráficos da mesma seção contribuem para a interpretação de que esta sucessão microfaciológica representa a progradação que modela a rampa carbonática, por fluxos gravitacionais ao longo do talude distal.
\end{abstract}

Palavras-chave: microfácies, Formação Cotinguiba, Cretáceo, Bacia de Sergipe-Alagoas.

\begin{abstract}
The Cenomanian-Turonian transition is globally recorded as the highest eustatic rise in the Cretaceous. In that context, the Cotinguiba Formation (Sergipe-Alagoas Basin) results from a transgression, which was responsible for building up a distally steepend carbonate ramp, during the drowning of the underlying platform system (until the mid Coniacian). These finegrained distal units are outcropping analogues of potential seals in Brazilian southeastern continental margin basins (e.g., Outeiro Formation, Campos Basin), which makes their facies analysis important in technological characterisation of petroleum systems they might be part of. Therefore, this study aims to characterise microfacies of a 100 metres well core section of the Cotinguiba Formation, in association with its stratigraphic context, in order to: define which sedimentological features are diagnostic of paleoenvironmental position; and thus analyse the paleoenvironment evolution, as recorded by the microfacies succession. For that, a sedimentological profile of the referred section was built, from which a complementary petrographic description was carried out and provided 11 microfacies (distinguished by compositional, textural and paleontological criteria). Biostratigraphic studies of this same section help to interpret this microfacies succession as the progradation that models the carbonate ramp with gravitational fluxes along the slope.
\end{abstract}

Keywords: microfacies, Cotinguiba Formation, Cretaceous, Sergipe-Alagoas Basin.

\section{INTRODUÇÃO}

À grande subida eustática cretácea (na transição Cenomaniano-Turoniano) é associado um fenômeno de anoxia oceânica global, responsável pela sedimentação de extensos depósitos pelíticos, ricos em matéria orgânica (Walter, 2000). Na Bacia de Sergipe-Alagoas, a Formação Cotinguiba resulta da transgressão iniciada no Cenomaniano, culminante no início do Turoniano, que acarretou na deposição de calcilutitos e margas sobre uma rampa carbonática, durante o afogamento do sistema plataformal sotoposto (Formação Riachuelo), até meados do Coniaciano (Berthou \& Bengtson, 1988). Tal seção é análoga, em termos paleoambientais, às que lhe são correlatas nas bacias da margem continental do sudeste brasileiro (e.g., Formação Outeiro, na Bacia de Campos): as litologias que a compõem 
se comportam como rochas-selante ou como potenciais reservatórios naturalmente fraturados.

Assim, sua análise faciológica é importante como base para caracterização tecnológica de sistemas petrolíferos em que participem, quando conjugada a estudos petrofísicos e geomecânicos.

Portanto, o objetivo deste trabalho é elaborar a caracterização microfaciológica de uma seção de $100 \mathrm{~m}$ de extensão em testemunho de sondagem da Formação Cotinguiba, associadamente ao seu contexto estratigráfico na sub-bacia de Sergipe, com as finalidades de: definir os atributos sedimentológicos diagnósticos da sua situação paleoambiental; e avaliar a evolução de paleoambientes registrada pela sucessão microfaciológica, assim estabelecida.

\section{MATERIAIS E MÉTODOS}

Um testemunho de sondagem de $440 \mathrm{~m}$ de extensão foi coletado na pedreira Votorantim, município de Laranjeiras, em Sergipe (Figura 1). Neste trabalho faz-se um recorte estratigráfico entre as profundidades de $50 \mathrm{~m}$ e $150 \mathrm{~m}$, posto que: os primeiros $50 \mathrm{~m}$ mostram-se muito alterados, por efeito de carstificação; e, além dos $150 \mathrm{~m}$, feições de tectonismo possivelmente inviabilizariam uma direta correlação faciológica deste com outros estudos.
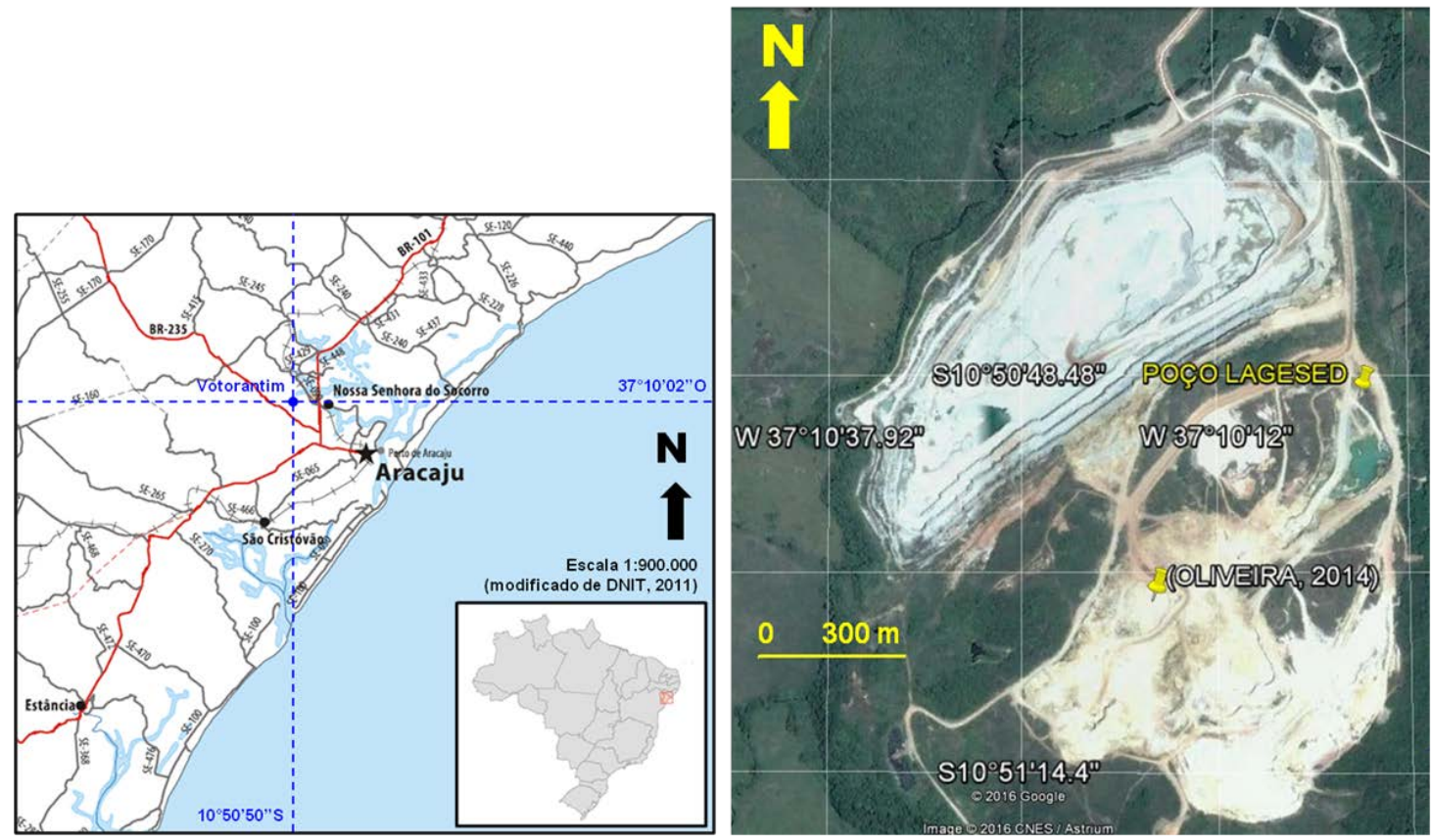

Figura 1 - Mapa de localização da pedreira Votorantim e principais vias de acesso (modificado de DNIT, 2011). Imagem de satélite com a localização de testemunhagem deste estudo ("POÇO LAGESED"; adaptação da imagem CNES/Astrium de 10/04/2015).

A sucessão dos litotipos identificados foi analisada, enfatizando-se os atributos: litologia (e grau de argilosidade), estrutura sedimentar, cor, fósseis (icnofósseis), feições diagenéticas (dolomitização, estilolitos, venulação e cavidades de dissolução) e estruturas (fraturas e falhas), resumidos num perfil sedimentológico na escala de 1: 40. Para o espectro granulométrico encontrado a classificação de Folk (1962) provou-se mais apropriada, por descrever macroscopicamente o tamanho médio dos grãos. Ressalta-se, porém, que a adoção do termo "folhelho calcífero" neste estudo serve a fins apenas descritivos (Pettijohn, 1957) de sua granulometria e fissilidade.

A caracterização litológica macroscópica foi complementada pela descrição petrográfica de
34 lâminas delgadas, distribuídas em média a cada $3 \mathrm{~m}$ da seção estudada. Nesta etapa, foram adotados sistemas de classificação: texturais, de Dunham (1962) com alterações de Embry \& Klovan (1971), que melhor descreve as variações verticais na sucessão sedimentar, através da comparação de litofácies deposicionais; composicionais, sensu Giannini (2000), que retrata os graus de alteração diagenética e de aloctonia das amostras; além de uma parametrização da abundância relativa de bioclastos, baseada naquela de Sliter (1999).

Ademais, a presente seção de estudo foi bioestratigraficamente analisada pelo geólogo Roberto Pereira (UFRJ), com base na última ocorrência de taxa guia dos nanofósseis calcários. Seus resultados confirmam que o 
intervalo entre $66 \mathrm{~m}$ e $138 \mathrm{~m}$ tem idade Turoniana inferior (biozona Radiolithus planus, N-260.3; sensu Antunes, 1998).

Os intervalos superiores e inferiores a este, segundo o autor, apresentam uma baixa recuperação e/ou má preservação de nanofósseis calcários, que impossibilitam uma resposta biocronoestratigráfica.

\section{CONTEXTO GEOLÓGICO}

A Bacia de Sergipe-Alagoas (SE-AL) localiza-se na região nordeste do Brasil, compreendendo uma área emersa de 15.000 $\mathrm{km}^{2}$, e uma porção submersa de aproximadamente $40.000 \mathrm{~km}^{2}$. Dadas as particularidades quanto ao preenchimento e evolução tectonosedimentar entre as porções sergipanas e alagoanas, neste trabalho designa-se por "subbacia de Sergipe” a porção da bacia limitada pelo Alto de Japoatã-Penedo e pela bacia de Jacuípe (Figura 2), embora o Alto de JapoatãPenedo não constitua um divisor de bacias (Neto et al., 2007).

Estruturalmente, a sub-bacia de Sergipe consiste de uma série de hemigrábens, regionalmente mergulhando de $10^{\circ}$ a $15^{\circ}$ a sudeste, em decorrência da orientação NE-SW do sistema de falhas normais, limitando-se a noroeste por um sistema de falhas lístricas normais e, a sul, pela zona de falhas de transferência de Vaza Barris.

Desse modo, a sedimentação carbonática e siliciclástica associada foi fortemente controlada por: subsidência diferencial; desenvolvimento de hemigrábens ao longo do falhamento extensional NE-SW; e estruturas secundárias derivadas do rebaixamento de capas, soerguimento de lapas e roll-overs (Koutsoukos et al., 1993).

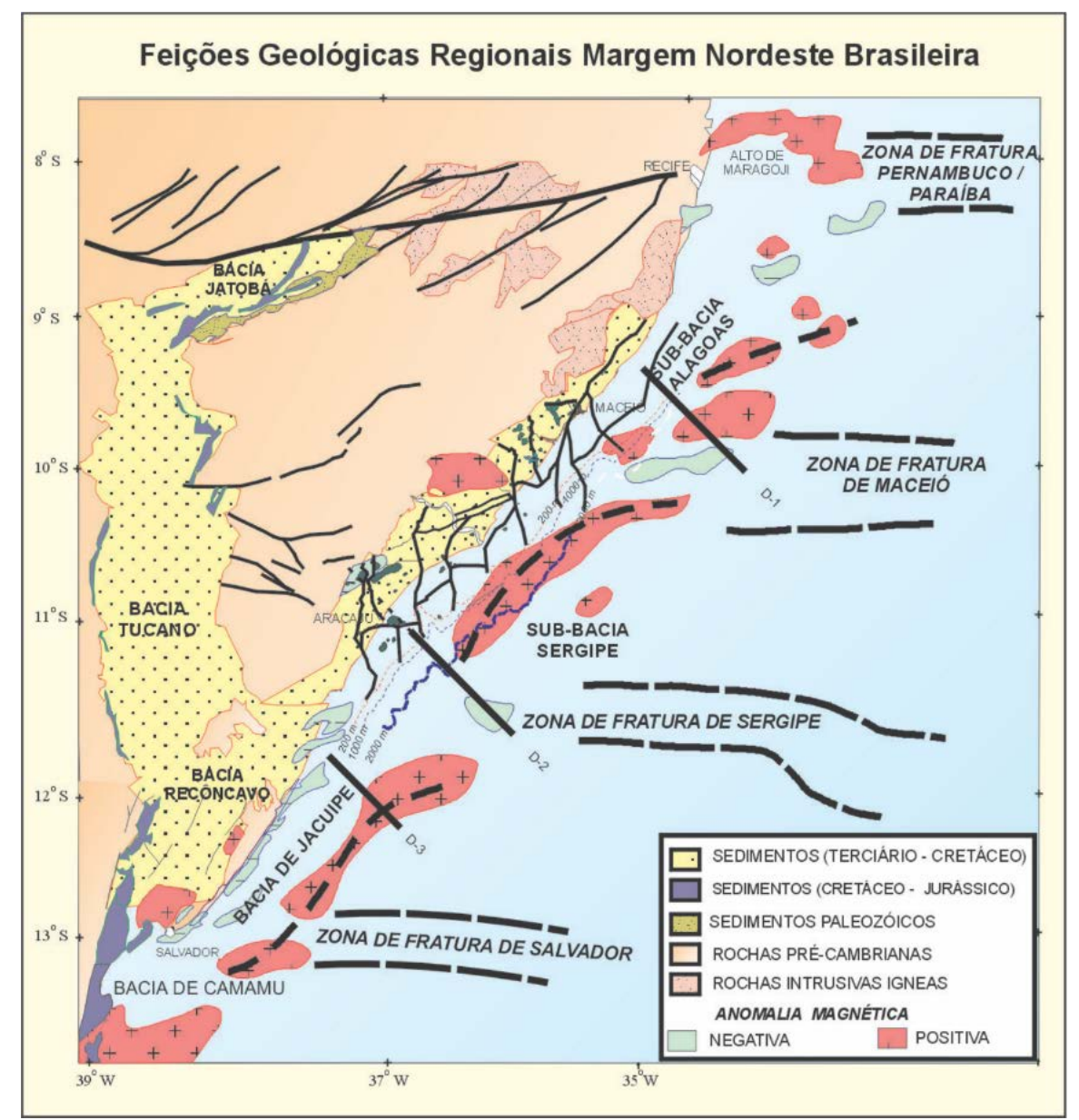

Figura 3 - Mapa tectônico esquemático da sub-bacia de Sergipe, mostrando anomalias magnéticas, alinhamentos de zonas de fraturas oceânicas e linhas sísmicas (D1, D2 e D3) (reproduzido de Mohriak, 2003).

Na sub-bacia de Sergipe observa-se uma das mais expressivas sucessões marinhas cretáceas dentre as bacias ao norte do Atlântico Sul, na qual a seção carbonática que se estende do Aptiano superior ao Coniaciano inferior (Figura
3) pode ser dividida em dois principais sistemas deposicionais (Koutsoukos et al., 1993): um sistema plataformal misto (carbonáticosiliciclástico), do Aptiano tardio ao Albiano (Formação Riachuelo); e um sistema 
plataformal carbonático, do Cenomaniano ao Eoconiaciano (Formação Cotinguiba), desenvolvido como uma sucessão maciça de carbonatos distais de grã fina; cujo contato na porção emersa da Bacia é marcado por discordâncias erosivas (Feijó, 1995).

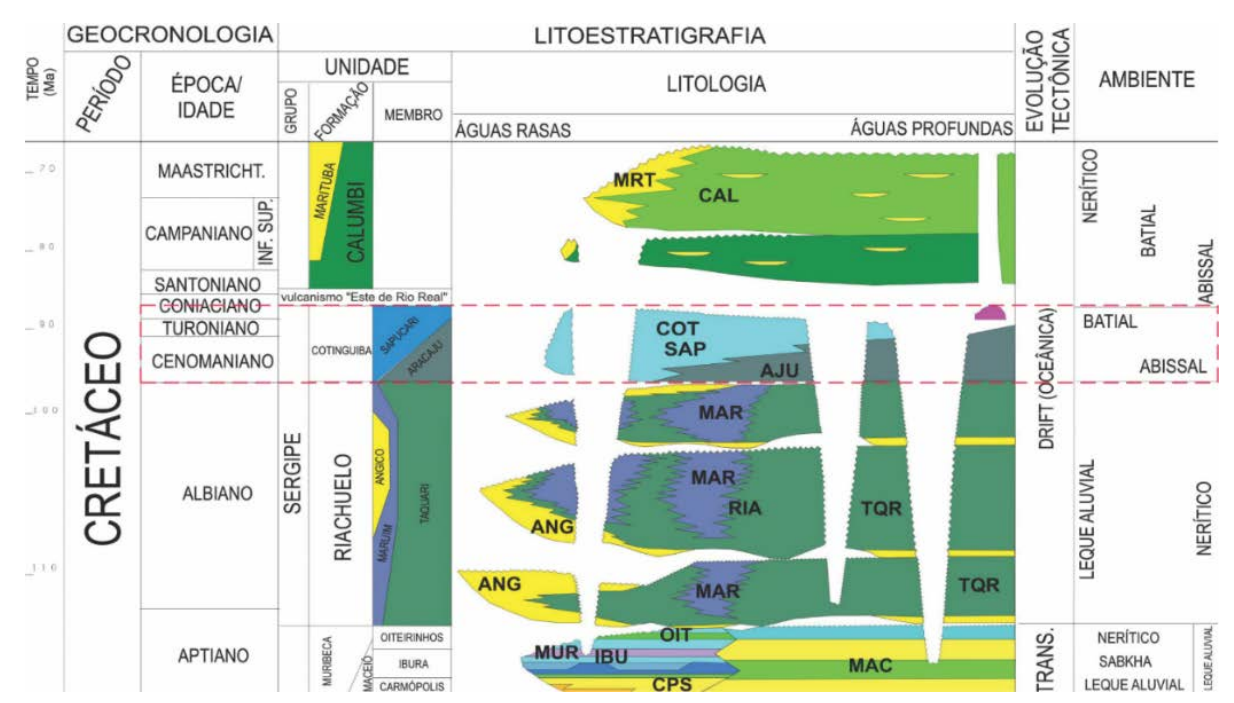

Figura 3 - Diagrama estratigráfico simplificado do Cretáceo marinho na sub-bacia de Sergipe (reproduzido de Santos, 2007), com destaque para a Formação Cotinguiba.

Os carbonatos da Formação Cotinguiba foram depositados em ambientes neríticos a batiais superiores de uma rampa carbonática, com condições de fundo disóxicas a francamente anóxicas, e de massas d’água epipelágicas bem oxigenadas. Essa sedimentação foi consequência de um aumento do nível relativo do mar (NRM), responsável pelo afogamento da plataforma carbonática de águas rasas da Formação Riachuelo (Koutsoukos et al., 1991).

Atualmente, a Formação Cotinguiba é individualizada nos Membros Sapucari e Aracajú (Koutsoukos et al., 1993): o primeiro (com espessura máxima de $800 \mathrm{~m}$ ), que consiste de mudstones e brechas carbonáticas subordinadas; gradando bacia adentro para as margas e folhelhos calcários do segundo, que pode atingir até 300 metros de espessura.

E segundo os mesmos autores, no Membro Sapucari (Figura 4) são reconhecidas duas fácies sedimentares: camadas rítmicas de margascalcilutitos, que apresentam boa laminação e horizontes de hardground (marcados por forte bioturbação); e brechas carbonáticas com estrutura maciça ou gradação normal, cujos clastos de wackestone contêm expressiva quantidade de fósseis (bivalves, gastrópodes, equinoides e foraminíferos planctônicos) desgastados por abrasão; ambas desenvolvidas sobre uma ampla rampa carbonática, com suaves declives topográficos e uma pequena quebra entre a plataforma rasa e regiões neríticas profundas.

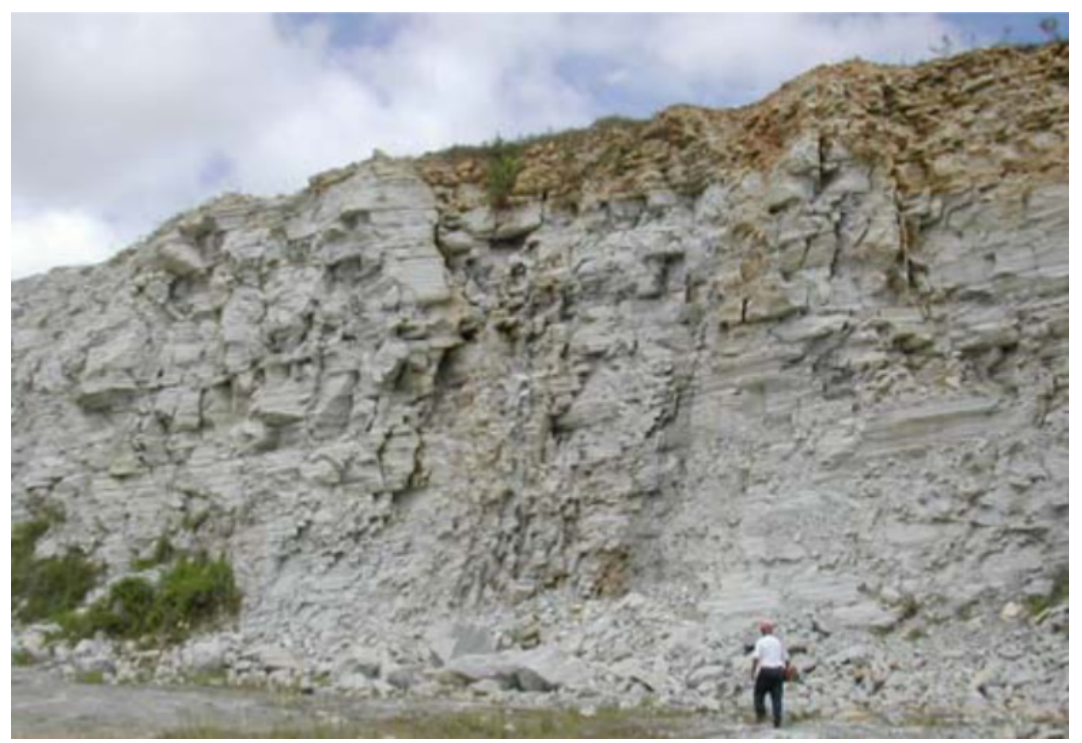

Figura 4 - Afloramento do Membro Sapucari, na pedreira Votorantim, Turoniano inferior a médio (Souza-Lima et al., 2002). 
Berthou e Bengtson (1988) advogam que o ambiente deposicional das porções atualmente terrestres da sub-bacia de Sergipe, do Cenomaniano inferior ao Coniaciano inferior, oscilou de águas profundas para águas rasas, regimes de plataforma externa e talude, também incluindo ambientes bacinais marinhosprofundos, embora provável e exclusivamente sobre a crosta continental.
E dessa forma, reconstruções paleogeográficas da porção terrestre atual da sub-bacia de Sergipe (Figura 5) sugerem um modelo um modelo de ampla rampa carbonática, com suaves declives topográficos e uma pequena quebra entre a plataforma rasa e regiões neríticas profundas, possivelmente herdada da quebra de talude da plataforma carbonática sotoposta (Koutsoukos et al., 1993).
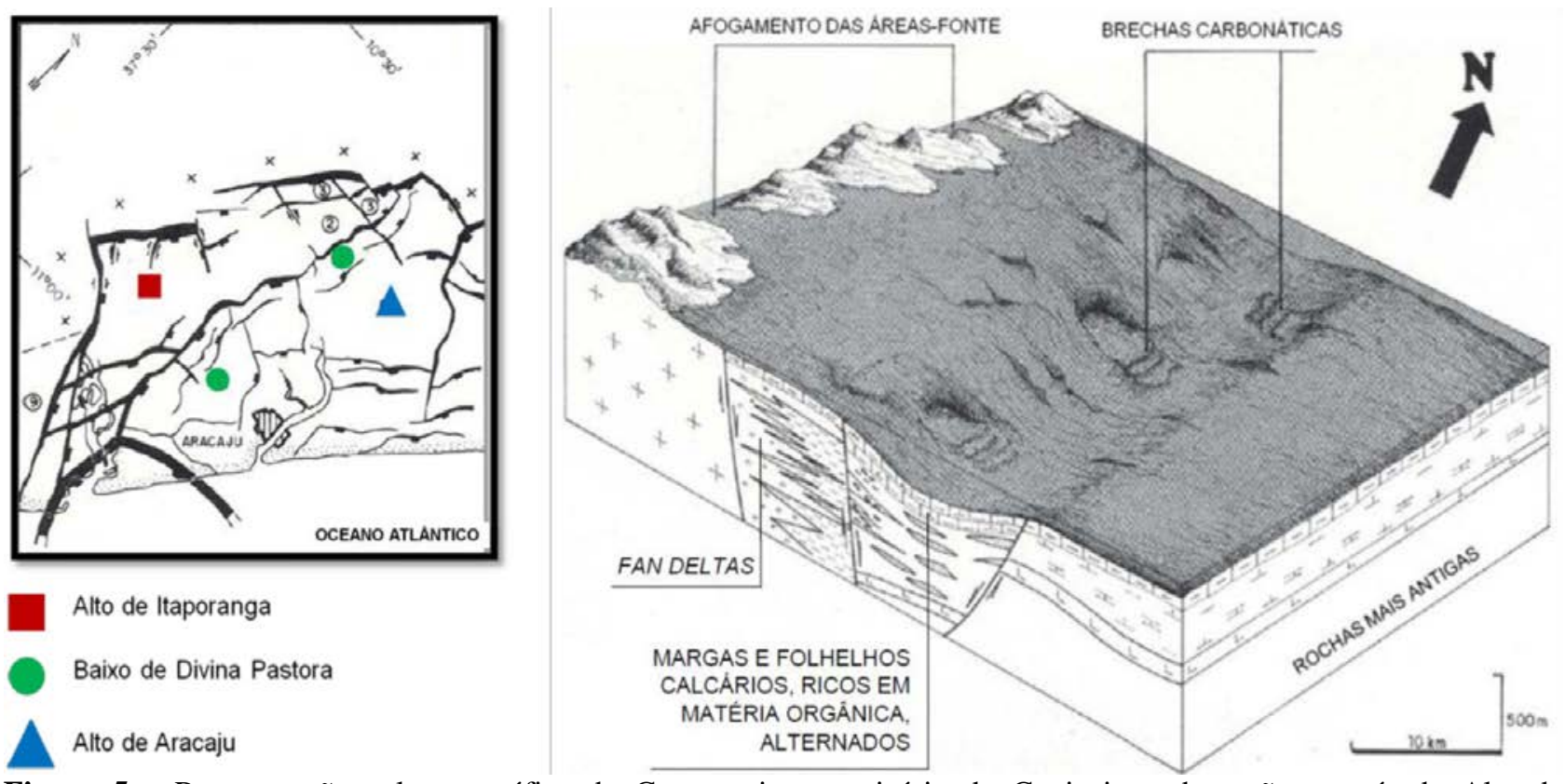

Figura 5 - Reconstrução paleogeográfica do Cenomaniano ao início do Coniaciano da seção através do Alto de Itaporanga, do Baixo de Divina Pastora e do Alto de Aracaju (modificado de Koutsoukos et al., 1993).

\section{RESULTADOS}

Os dados macroscopicamente descritivos da seção estudada foram categorizados em (Figura 6): aspectos litológico-texturais; feições estruturais; feições diagenéticas; e feições indicativas de bioturbação. Assinala-se também no perfil os pontos de amostragem petrográfica (com os respectivos números de lâminas delgadas, confeccionadas).

Ante a impossibilidade de discernir a granulometria da maior parte da seção estudada (mesmo com auxílio do estereomicroscópio),convencionou-se

representá-la inteiramente na fração argila, exceto duas ocorrências rudíticas (Figura 7): o calcirrudito grosso brechoide, aos 110,6 m de profundidade; e o calcirrudito grosso coquinoide, entre $52,7 \mathrm{~m}$ e $54,70 \mathrm{~m}$ de profundidade. $\mathrm{Na}$ primeira observam-se: diferentes fases de brechamento, matrizsuportadas, que exibem ligeira granodecrescência ascendente; intraclastos subarredondados, contendo fragmentos milimétricos de conchas (macroscopicamente indis- tintas); e um nítido contato basal erosivo; que conjuntamente tipificam processos de escorregamento. Já o calcirrudito grosso coquinoide apresenta: uma proporção de matriz lamosa significativamente maior; e seu arcabouço é composto por bioclastos milimétricos a centimétricos (fragmentos carbonáticos de bivalves, presumivelmente), deformados e recristalizados (aparentemente por efeito de neomorfismo), e sem orientação aparente; que caracterizam o contato entre as conchas e outros bioclastos durante 0 transporte por correntes (Walter, 2000).

Os calcilutitos dessa seção apresentam mais comumente nódulos e superfícies de silicificação, além de laminações marcadas por recorrentes superfícies de compactação química, que apresentam inclinações médias de $10^{\circ}$ a $15^{\circ}$ (em relação à direção de perfuração do poço), mas que localmente atingem valores de $0^{\circ}$ e até $25^{\circ}$ - inflexões que concordam com a ocorrência de falhas e espelhos de falhas. O espaçamento com que 


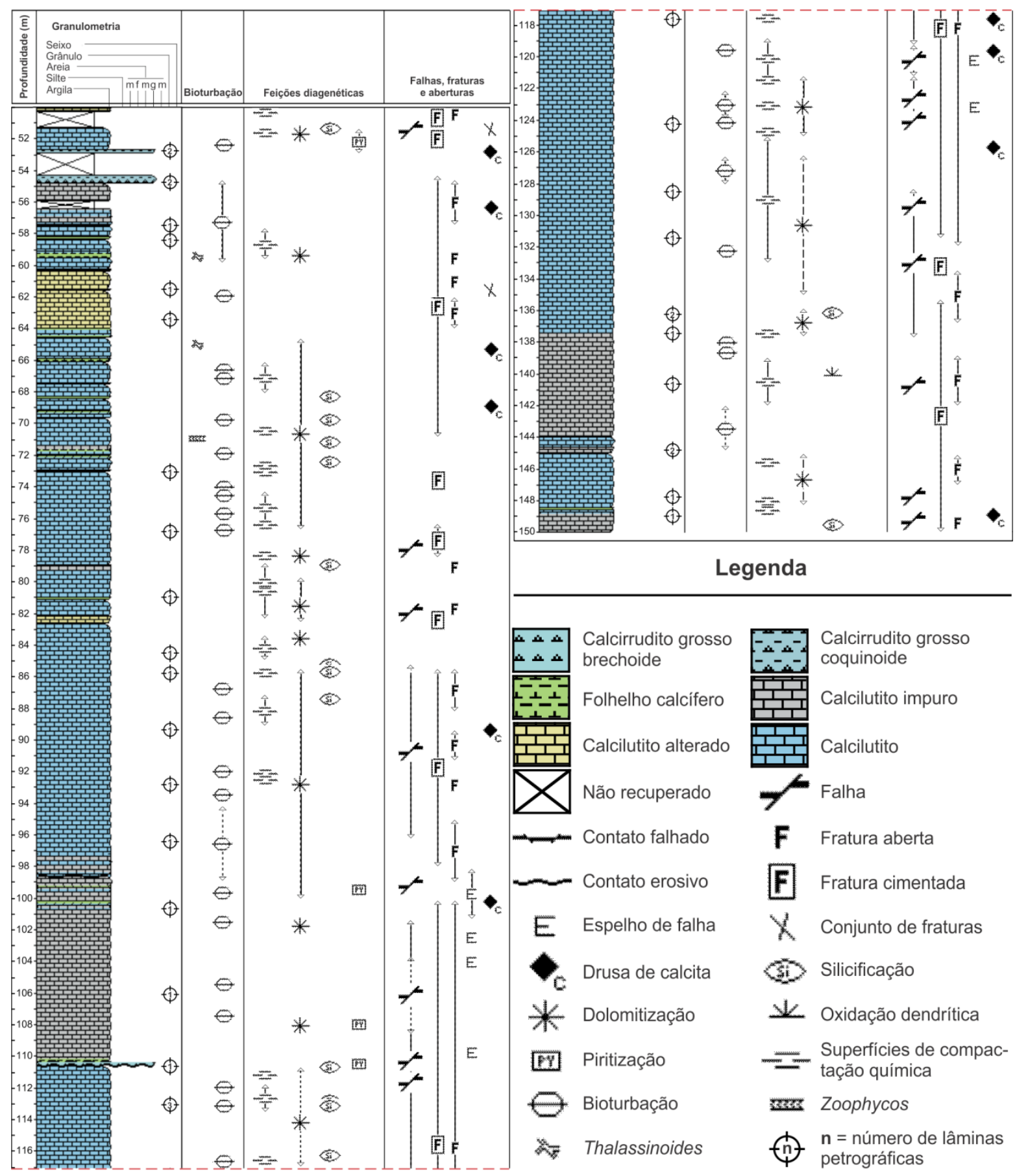

Figura 6 - Perfil sedimentológico da seção estudada, na escala original de 1:200. O perfil está segmentado na figura (pela linha tracejada vermelha) aos $117 \mathrm{~m}$. Diferem-se os litotipos conforme a escala granulométrica de Folk (1962) para rochas carbonáticas. A distinção de “impuro” segue a classificação de Giannini (2000).

ocorrem varia de decímetros a menos de $1 \mathrm{~mm}$, ao ponto de amalgamarem-se e gerar os "folhelhos calcíferos". Estes últimos, periódicamente recorrentes, assinalam superfícies de maior compactação química do pacote pelágico, i.e., maior transferência de solução (Scholle et al., 1983).

Em notável alternância com os calcilutitos, ocorrem os calcilutitos impuros, mais escuros, nos quais infere-se maiores teores de terrígenos camadas originalmente mais espessas e mais pobres em carbonato que reduziram de volume, submetidas à exportação de maiores volumes do seu material carbonático original. Além destes, também são registrados "calcilutitos alterados", que apresentam colorações amareladas e alterações cársticas, intensas ao ponto de obliterar suas feições sedimentológicas. Nesses intervalos é comum a ocorrência de cavidades centimétricas e conjuntos de fraturas, que parecem ter sido hidraulicamente ativas, propiciando a migração do fluido diagenético (o que é condizente com o fato de restringem-se à porção superior do testemunho, mais fraturada). 

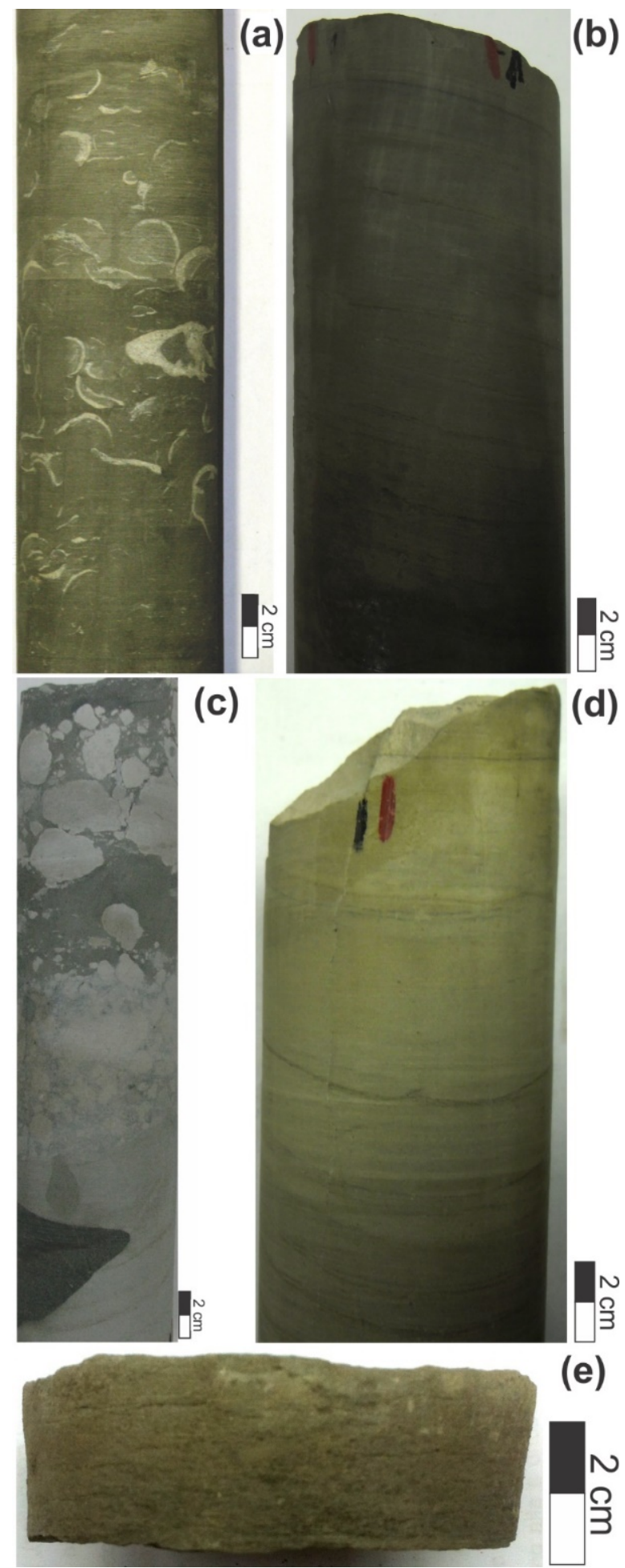

Figura 7 - Litotipos representativos da seção estudada: (a) calcirrudito grosso coquinoide (ca. 52,7 m); (b) calcilutito impuro; (c) calcirrudito grosso brechoide (ca. 110,6 m); (d) calcilutito; e (e) folhelho calcífero.

Ao longo do perfil sedimentológico da figura 6 foram ainda descritas feições sugestivas de bioturbação - por pertubações das estruturas laminares, pela formação de nódulos de cimentação diferenciada, ou por indícios de fósseis-traço.

Não obstante a forte interferência diagenética, em determinados níveis do testemunho são reconhecidos os icnogêneros (Figura 8): Thalassinoides, em 64,9 m e 64,9 m; e Zoophycos, em 70,9 m.

Os atributos sedimentológicos mais prontamente observáveis em lâmina delgada foram tabulados segundo seus aspectos (tabela 1): litológicos-composicionais (Giannini, 2000), texturais (Dunham, 1962) e de abundância relativa dos bioclastos (Sliter, 1999).

A dolomitização, frequentemente associada a processos de neomorfismo, oblitera parcial ou totalmente a trama primária das amostras, de 

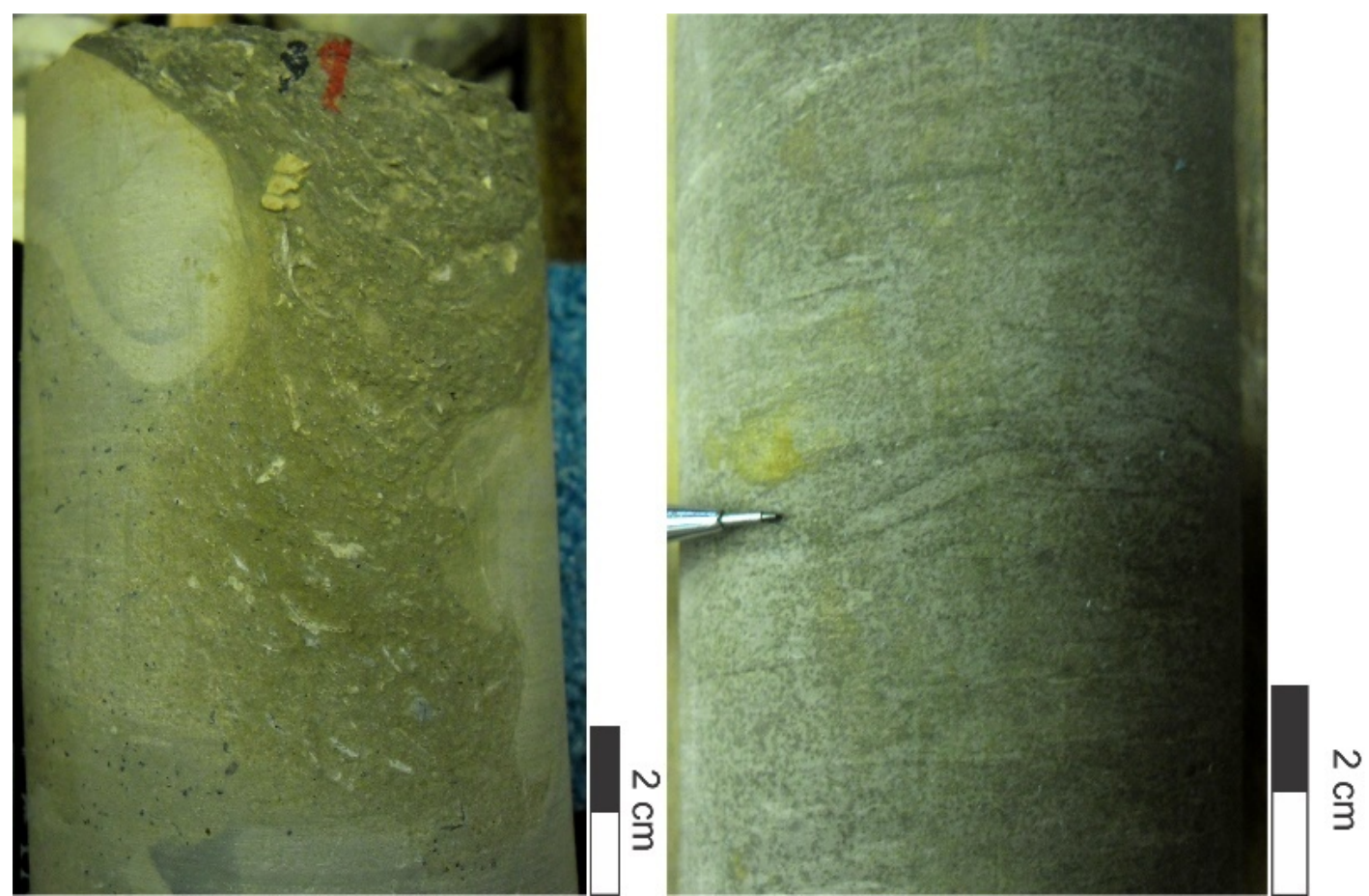

Figura 8 - Icnogêneros Thalassinoides (à esquerda) e Zoophycos (à direita) da seção estudada. A transição do preenchimento do Thalassinoides por sedimentos sem estruturas para uma laminação paralela indica sedimentação gravitacional. E a seção transversal de um espraite (estrutura sinuosa composta por buracos, justapostos, de residência ou alimentação de organismo vermiforme) de Zoophycos evidencia o caminho do aparelho alimentador durante a sondagem do sedimento em mar profundo (Chamberlain, 1978).

modo que naquelas mais dolomitizadas, quando possível, são feitas inferências quanto à textura deposicional nas porções de menor energia. E os teores de impurezas podem indicar maiores aportes da rampa interna ou central (aloctonia), o que deve ser corroborado pela assembleia fossilífera. No entanto, há que se considerar os efeitos de compactação química, que concentram materiais residuais (grãos siliciclásticos, inclusive)

A limitada abrangência textural geral oferece indícios paleodeposicionais de baixa energia, condizentes com o contexto geológico regional: extensos pacotes lamosos, bioclásticos, matriz-suportados, que sugerem processos de decantação em fundo marinho; o que é ratificado pelos recorrentes traços de polinucleação de romboedros dolomíticos, característicos de sedimentos lamosos (Flügel, 2010).

As estimativas de abundância relativa da assembleia fossilífera também sofrem forte influência dos processos de dolomitização, de modo que devem ser lidas como índices de proporção entre bioclastos identificáveis em lâmina delgada.

E além das limitações à descrição petrográfica de tais bioclastos, ressalta-se que a diversidade em lâminas delgadas não necessariamente corresponde àquela da biota no paleoambiente deposicional, de forma que as análises semiquantitativas de abundância apenas auxiliam inferir-lhes os paleoambientes.

Verifica-se que as transferências de solução nesses pacotes pelágicos ocorreram ao longo de microestilólitos (o que evidencia profundidades de soterramento de centenas de metros e suturas de dissolução.

A dolomitização (e, eventualmente, dedolomitização) amplamente distribuída, sugere altas temperaturas atingidas em soterramento (juntamente a composições modificadas da água nos poros), além de um teor de carbono orgânico consideravelmente alto (cc. modelo de dolomitização em soterramento, sensu Scholle \& Ulmer-Scholle, 2003, p. 372).

A tais depósitos de mar profundo, sob as baixas taxas de sedimentação pelágica, somamse: a escassez de fauna bentônica e estruturas de laminação, que denotam condições de deficiência em oxigênio (Walter, 2000); e uma profusa piritização (posterior às dolomitas), que também indica relativa abundância de carbono orgânico; de modo que se inferem ambientes de alta produtividade, sob a influência da zona de mínimo oxigênio (Von Stackelberg, 1972; cf. Walter, 2000). 
Tabela 1 - Descrições petrográficas segundo os atributos diagnósticos de microfácies. São definidas as seguintes reduções para a tabela: “calcisf.” (calcisferas); “radiol.” (radiolários); "gastróp.” (gastrópodes); “foram. planct.” (foraminíferos planctônicos); “foram. bent.” (foraminíferos bentônicos); “esp. esp.” (espículas de esponja); "roveacr.” (roveacrinídeos); “equin.” (fragmentos de equinoides); "grãos fosf.” (grãos e fragmentos fosfáticos); “algas” (fragmentos de algas verdes); "bivalves” (fragmentos de bivalves); “inocer.” (fragmentos de inoceramídeos); e "ostrac.” (fragmentos de ostracode).

\begin{tabular}{|c|c|c|c|c|c|c|c|c|c|c|c|c|c|}
\hline \multirow{2}{*}{\begin{tabular}{|c|} 
Amostras \\
petrográficas
\end{tabular}} & \multicolumn{5}{|c|}{ LITOLOGIA } & \multicolumn{2}{|c|}{ TEXTURA } & \multicolumn{6}{|c|}{ ABUNDÂNCIA RELATIVA DOS BIOCLASTOS } \\
\hline & 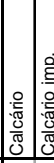 & 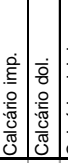 & 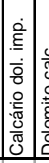 & 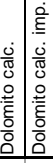 & 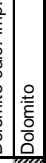 & 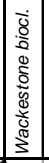 & 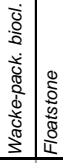 & 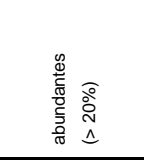 & 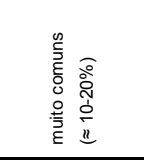 & 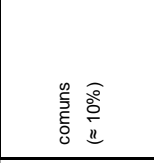 & 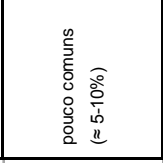 & 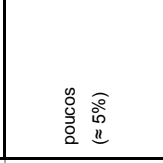 & 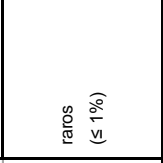 \\
\hline 52,65 & & & & & & & & inocer.(?) & & radiol. & & grãos fosf. & \\
\hline 52,75 & & & & & & & & inocer.(?) & & radiol. & & grãos fosf. & \\
\hline 54,70 & & & & & & & & & & & & & \\
\hline 54,75 & & & & & & & & & & grãos fosf., equin. & radiol. & foram. planct. & \\
\hline 57,50 & & & & & & & & equin. & calcisf. & & $\begin{array}{l}\text { grãos fosf., esp. } \\
\text { esp. }\end{array}$ & inocer. & \\
\hline 58,50 & & & & & & & & & equin. & foram. planct. & grãos fosf., calcisf. & $\begin{array}{l}\text { esp. esp., bivalves, } \\
\text { inocer., radiol. }\end{array}$ & ostrac., roveacr. \\
\hline 61,50 & & & & & & & & calcisf. & foram. planct. & radiol., bivalves & equin., gastróp. & & $\begin{array}{c}\text { grãos fosf., foram. } \\
\text { bent. }\end{array}$ \\
\hline 63,40 & & & & & & & & calcisf. & foram. planct. & gastróp. & & inocer., radiol. & $\begin{array}{l}\text { grãos fosf., foram. } \\
\text { bent., esp. esp., } \\
\text { equin. }\end{array}$ \\
\hline 73,10 & & & & & & & & $\begin{array}{l}\text { foram. planct., } \\
\text { calcisf. }\end{array}$ & equin. & & bivalves, inocer. & $\begin{array}{l}\text { gastróp., grãos } \\
\text { fosf. }\end{array}$ & roveacr. \\
\hline 76,85 & & & & & & & & & equin., calcisf. & $\begin{array}{l}\text { foram. planct., } \\
\text { radiol. }\end{array}$ & & $\begin{array}{l}\text { grãos fosf., } \\
\text { gastróp. }\end{array}$ & ostrac., roveacr. \\
\hline 81,00 & & & & & & & & & calcisf. & radiol. & & $\begin{array}{l}\text { foram. planct., } \\
\text { bivalves, equin. }\end{array}$ & $\begin{array}{l}\text { grãos fosf., esp. } \\
\text { esp. }\end{array}$ \\
\hline 84,50 & & & & & & & & calcisf. & & $\begin{array}{l}\text { foram. planct., } \\
\text { radiol. }\end{array}$ & equin. & $\begin{array}{l}\text { foram. bent., } \\
\text { bivalves }\end{array}$ & $\begin{array}{l}\text { esp. esp., roveacr., } \\
\text { grãos fosf. }\end{array}$ \\
\hline 85,80 & & & & & & & & & $\begin{array}{l}\text { foram. planct., } \\
\text { equin. }\end{array}$ & calcisf., bivalves & radiol. & inocer. & $\begin{array}{l}\text { roveacr., grãos } \\
\text { fosf. }\end{array}$ \\
\hline 89,40 & & & & & & & & calcisf. & & $\begin{array}{l}\text { foram. planct., } \\
\text { radiol. }\end{array}$ & & $\begin{array}{l}\text { bivalves, inocer., } \\
\text { frag. esp. }\end{array}$ & \\
\hline 92,85 & & & & & & & & & foram. planct. & inocer., calcisf. & equin. & $\begin{array}{l}\text { esp. esp., radiol., } \\
\text { bivalves }\end{array}$ & grãos fosf. \\
\hline 96,40 & & & & & & & & & $\begin{array}{l}\text { calcisf., foram. } \\
\text { planct. }\end{array}$ & radiol. & equin., inocer. & $\begin{array}{l}\text { foram. bent., } \\
\text { gastróp., esp. } \\
\text { esp., roveacr. }\end{array}$ & grãos fosf. \\
\hline 100,65 & & & & & & & & calcisf. & & $\begin{array}{l}\text { radiol., foram. } \\
\text { planct. }\end{array}$ & equin. & $\begin{array}{l}\text { roveacr., bivalves, } \\
\text { inocer., foram. } \\
\text { bent. }\end{array}$ & \\
\hline 106,10 & & & & & & & & calcisf. & foram. planct. & equin., gastróp. & radiol. & inocer., ostrac. & $\begin{array}{l}\text { grãos fosf., } \\
\text { roveacr., algas }\end{array}$ \\
\hline 110,60 & & & & & & & & calcisf. & equin., gastróp. & $\begin{array}{l}\text { foram. planct., } \\
\text { radiol. }\end{array}$ & bivalves, roveacr. & ostrac. & $\begin{array}{l}\text { foram. bent., } \\
\text { inocer. }\end{array}$ \\
\hline $\begin{array}{l}112,95 \\
113,00 \\
113,05\end{array}$ & & & & & & & & & $\begin{array}{l}\text { foram. planct., } \\
\text { calcisf., bivalves }\end{array}$ & gastróp. & radiol., equin. & foram. bent. & $\begin{array}{l}\text { grãos fosf., algas, } \\
\text { inocer. }\end{array}$ \\
\hline 117,20 & & & & & & & & & calcisf. & gastróp. & $\begin{array}{l}\text { foram. planct., } \\
\text { radiol. }\end{array}$ & $\begin{array}{l}\text { foram. bent., } \\
\text { inocer., equin., } \\
\text { bivalves, roveacr. }\end{array}$ & $\begin{array}{l}\text { grãos fosf., esp. } \\
\text { esp. }\end{array}$ \\
\hline 124,20 & & & & & & & & & & calcisf., radiol. & equin. & $\begin{array}{l}\text { gastróp., foram. } \\
\text { planct. }\end{array}$ & $\begin{array}{l}\text { grãos fosf., esp. } \\
\text { esp., bivalves, } \\
\text { roveacr. }\end{array}$ \\
\hline 128,50 & & & & & & & & & calcisf. & radiol. & $\begin{array}{l}\text { algas, equin., } \\
\text { gastróp. }\end{array}$ & $\begin{array}{l}\text { foram. planct., } \\
\text { roveacr., inocer. }\end{array}$ & $\begin{array}{l}\text { esp. esp., foram. } \\
\text { bent., bivalves, } \\
\text { grãos fosf. }\end{array}$ \\
\hline 131,40 & & & & & & & & & & calcisf. & $\begin{array}{l}\text { equin., gastróp., } \\
\text { foram. planct. }\end{array}$ & radiol., bivalves & roveacr. \\
\hline $\begin{array}{l}136,10 \mathrm{~A} \\
136,10 \mathrm{~B}\end{array}$ & & & & & & & & & calcisf., radiol. & foram. planct. & bivalves & equin. & $\begin{array}{l}\text { esp. esp., grãos } \\
\text { fosf. }\end{array}$ \\
\hline 137,50 & & & & & & & & & & equin. & calcisf. & $\begin{array}{l}\text { esp. esp., foram. } \\
\text { planct., radiol. }\end{array}$ & $\begin{array}{l}\text { algas, roveacr., } \\
\text { grãos fosf. }\end{array}$ \\
\hline 140,70 & & & & & & & & calcisf. & & & foram. planct. & $\begin{array}{l}\text { gastróp., radiol., } \\
\text { equin., esp. esp. }\end{array}$ & ostrac., grãos fosf. \\
\hline $\begin{array}{l}144,80 \mathrm{~A} \\
144,80 \mathrm{~B}\end{array}$ & & & & & & & & & & & foram. planct. & & $\begin{array}{l}\text { esp. esp., grãos } \\
\text { fosf. }\end{array}$ \\
\hline 147,80 & & & & & & & & & calcisf., radiol. & $\begin{array}{l}\text { gastróp., foram. } \\
\text { planct. }\end{array}$ & & bivalves, roveacr. & $\begin{array}{l}\text { equin., foram. } \\
\text { bent. }\end{array}$ \\
\hline 149,00 & & & & & & & & & & & & $\begin{array}{l}\text { esp. esp., calcisf., } \\
\text { foram. planct. }\end{array}$ & grãos fosf. \\
\hline
\end{tabular}




\section{DISCUSSÕES}

A continuidade vertical das intercalações pelágicas, que se evidencia no perfil da figura 7 , reflete o equilíbrio entre o aporte sedimentar e processos de erosão e dissolução. Tal acamamento rítmico deve ser provocado por flutuações no ambiente deposicional que, influenciadas pelos ciclos orbitais, variam em função de: aporte terrígeno; produtividade em superfície contra taxas de dissolução; velocidades de corrente; e profundidade d'água (Scholle e Ulmer-Scholle, 2003).

Entretanto, existe estreita correspondência entre a incidência de hiatos deposicionais em mar profundo com o nível do mar, mudanças climáticas e variações na circulação de fundo (Moore et al., 1978). Isto é exemplificado na ocorrência de Thalassinoides da amostra 64,90 $\mathrm{m}$, que assinala uma nítida superfície de omissão (Figura 8). Esta superfície pode estar associada à acentuada seção condensada, que se registra nas curvas eustáticas de $\mathrm{Haq}$ et al. (1988) (Figura 9), e que corresponde precisamente ao limite do Turoniano inferior.

Assim, poderiam ser igualmente aplicadas as interpretações estratigráficas de Pereira (1994), que qualificam as sequências anteriores $\mathrm{e}$ posteriores a esse limite, respectivamente, como: trato de sistemas transgressivo e trato de sistemas de mar alto. Com efeito, essa seção fortemente condensada representa a desaceleração das taxas deposicionais já próximas ao Turoniano médio (Berthou e Bengtson, 1988) e pode ser interpretada como uma superfície de inundação máxima, que traça o fim da transgressão marinha e marca o limite das referidas sequências.

Berthou e Bengtson (1988) afirmam também que do Turoniano tardio ao início do Coniaciano ocorre um pico na taxa de deposição, seguido de uma regressão nas áreas marginais da Bacia, possivelmente causada por seu basculamento para o mar - o que implica em dizer que, juntamente à subida do NRM (em contínua desaceleração, por controle eustático), as taxas de aporte sedimentar (e, logo, de produtividade carbonática da rampa) eram ascendentes e culminaram ao final do Turoniano.

Assim sendo, a regressão nas áreas marginais da sub-bacia de Sergipe, posteriormente registrada, pode ser atribuída a um evento de regressão normal, no qual o aporte sedimentar (e logo, as taxas de acomodação) supera a subida do NRM.

Dessa forma, as amostras petrográficas da tabela 1 foram microfaciologicamente classificadas, em função dos mesmos atributos diagnósticos: composições mineralógicas (sensu Giannini, 2000); texturas (Dunham, 1962); e abundâncias relativas dos bioclastos (adaptado de Sliter, 1999); que se distribuem na sucessão sedimentar do testemunho estudado (tabela 2).

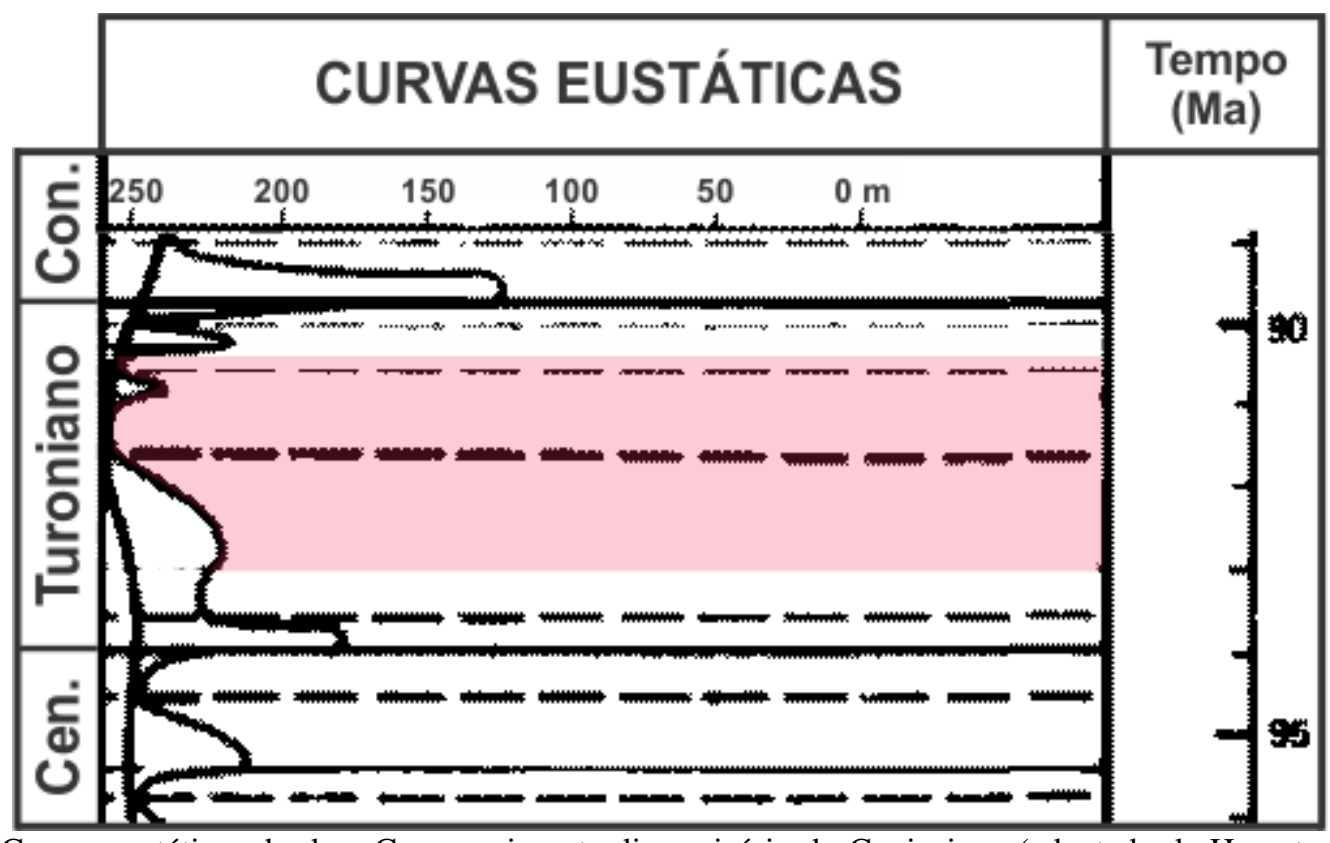

Figura 9 - Curvas eustáticas desde o Cenomaniano tardio ao início do Coniaciano (adaptado de Haq et al., 1988). As curvas representam ciclos de terceira (1-10 Ma) e de segunda ordem (envoltória: 10-100 Ma). As linhas horizontais tracejadas representam seções condensadas (divididas em três ordens de magnitude relativa, conforme a espessura da linha). A faixa destacada em vermelho engloba (pelo menos parcialmente) o recorte temporal proposto para o testemunho estudado. 
Tabela 2 - Classificação microfaciológica das amostras petrográficas.

\begin{tabular}{|c|c|c|c|}
\hline MICROFÁCIES & $\begin{array}{c}\text { Litologia } \\
\text { (GIANNINI, 2000) }\end{array}$ & $\begin{array}{c}\text { Textura } \\
\text { (DUNHAM, 1962) } \\
\end{array}$ & $\begin{array}{l}\text { Abundância relativa de bioclastos } \\
\text { (modificado de SLITER, 1999) }\end{array}$ \\
\hline $\begin{array}{c}\text { MF.1 } \\
(52,65 \mathrm{~m}- \\
54,70 \mathrm{~m})\end{array}$ & $\begin{array}{l}\text { Dolomito calcítico } \\
\text { impuro a dolomito }\end{array}$ & $\begin{array}{c}\text { Mudstone ou } \\
\text { Wackestone } \\
\text { bioclástico }\end{array}$ & $\begin{array}{l}\text { Abundantes inoceramídeos silicificados; comuns radiolários; e } \\
\text { poucos grãos fosfáticos esqueletais. }\end{array}$ \\
\hline $\begin{array}{c}\text { MF.2 } \\
(54,75 \mathrm{~m}- \\
58,50 \mathrm{~m}) \\
\end{array}$ & $\begin{array}{l}\text { Calcário impuro a } \\
\text { dolomito calcítico } \\
\text { impuro }\end{array}$ & $\begin{array}{c}\text { Mudstone ou } \\
\text { Wackestone } \\
\text { bioclástico }\end{array}$ & $\begin{array}{l}\text { Equinoides sub-milimétricos a milimétricos, comuns a abundantes; } \\
\text { grãos fosfáticos esqueletais, sub-milimétricos a milimétricos, pouco } \\
\text { comuns a comuns. }\end{array}$ \\
\hline $\begin{array}{c}\text { MF.3 } \\
(61,50 \mathrm{~m}- \\
63,40 \mathrm{~m})\end{array}$ & $\begin{array}{l}\text { Calcário a calcário } \\
\text { dolomítico }\end{array}$ & $\begin{array}{l}\text { Wackestone } \\
\text { bioclástico }\end{array}$ & $\begin{array}{l}\text { Abundantes calcisferas; foraminíferos planctônicos muito comuns; } \\
\text { gastrópodes pouco comuns a comuns; radiolários poucos a comuns; } \\
\text { raros grãos fosfáticos esqueletais e foraminíferos bentônicos. }\end{array}$ \\
\hline $\begin{array}{c}\text { MF.4 } \\
(73,10 \mathrm{~m}- \\
76,85 \mathrm{~m})\end{array}$ & $\begin{array}{l}\text { Calcário impuro a } \\
\text { dolomito calcítico } \\
\text { impuro }\end{array}$ & $\begin{array}{c}\text { Wackestone ou } \\
\text { wacke- a } \\
\text { packstone }\end{array}$ & $\begin{array}{l}\text { Muito comuns equinoides, sub-milimétricos a milimétricos; } \\
\text { foraminíferos planctônicos comuns a abundantes; poucos } \\
\text { gastrópodes e grãos fosfáticos esqueletais; e raros roveacrinídeos. }\end{array}$ \\
\hline $\begin{array}{c}\text { MF.5 } \\
(81,00 \mathrm{~m}- \\
89,40 \mathrm{~m}) \\
\end{array}$ & $\begin{array}{l}\text { Calcário ou calcário } \\
\text { dolomítico a calcário } \\
\text { dolomítico impuro }\end{array}$ & $\begin{array}{c}\text { Wackestone ou } \\
\text { wacke- a } \\
\text { packstone }\end{array}$ & $\begin{array}{c}\text { Calcisferas comuns a abundantes; foraminíferos planctônicos poucos } \\
\text { a muito comuns; bivalves poucos a comuns; radiolários pouco } \\
\text { comuns a comuns; e raros grãos fosfáticos. }\end{array}$ \\
\hline $\begin{array}{c}\text { MF.6 } \\
(92,85 \mathrm{~m}- \\
106,10 \mathrm{~m}) \\
\end{array}$ & $\begin{array}{l}\text { Calcário a calcário } \\
\text { impuro }\end{array}$ & $\begin{array}{c}\text { Wackestone ou } \\
\text { wacke- a } \\
\text { packstone }\end{array}$ & $\begin{array}{c}\text { Calcisferas comuns a abundantes; foraminíferos planctônicos } \\
\text { comuns a muito comuns; radiolários pouco a comuns; poucos a } \\
\text { comuns inoceramídeos; poucos a comuns equinoides. }\end{array}$ \\
\hline $\begin{array}{c}\text { MF.7 } \\
(110,60 \mathrm{~m})\end{array}$ & Calcário & Floatstone & $\begin{array}{l}\text { Abundantes calcisferas; equinoides e gastrópodes muito comuns; } \\
\text { comuns foraminíferos planctônicos e radiolários; bivalves e } \\
\text { roveacrinídeos pouco comuns; e poucos ostracodes. }\end{array}$ \\
\hline $\begin{array}{l}\text { MF.8 } \\
(112,95 \mathrm{~m}- \\
124,20 \mathrm{~m})\end{array}$ & $\begin{array}{l}\text { Calcário, calcário } \\
\text { dolomítico ou } \\
\text { dolomito calcítico }\end{array}$ & $\begin{array}{l}\text { Mudstone ou } \\
\text { Wackestone } \\
\text { bioclástico }\end{array}$ & $\begin{array}{l}\text { Calcisferas comuns a muito comuns; foraminíferos planctônicos } \\
\text { poucos a muito comuns; gastrópodes poucos a muito comuns; } \\
\text { radiolários poucos a muito comuns; bivalves raros a muito comuns; e } \\
\text { raros grãos fosfáticos esqueletais. }\end{array}$ \\
\hline $\begin{array}{c}\text { MF.9 } \\
(128,50 \mathrm{~m}- \\
136,10 \mathrm{~m}) \\
\end{array}$ & Calcário & $\begin{array}{l}\text { Wackestone } \\
\text { bioclástico }\end{array}$ & $\begin{array}{c}\text { Calcisferas comuns a muito comuns; radiolários poucos a muito } \\
\text { comuns; foraminíferos planctônicos poucos a muito comuns; poucos } \\
\text { a pouco comuns equinoides; e bivalves raros a pouco comuns. }\end{array}$ \\
\hline \multirow{2}{*}{$\begin{array}{l}\text { MF.10 } \\
(137,50 \mathrm{~m}- \\
147,80 \mathrm{~m})\end{array}$} & Calcário dolomítico & $\begin{array}{c}\text { Mudstone ou } \\
\text { Wackestone } \\
\text { bioclástico }\end{array}$ & $\begin{array}{l}\text { Foraminíferos planctônicos poucos a pouco comuns; raras a poucas } \\
\text { espículas de esponjas; e raros grãos fosfáticos. }\end{array}$ \\
\hline & Calcário & $\begin{array}{l}\text { Wackestone ou } \\
\text { wacke- a } \\
\text { packstone }\end{array}$ & $\begin{array}{l}\text { Calcisferas muito comuns a abundantes; radiolários poucos a muito } \\
\text { comuns; poucos a comuns gastrópodes; foraminíferos planctônicos } \\
\text { pouco comuns a comuns; e raros a poucos equinoides. }\end{array}$ \\
\hline $\begin{array}{c}\text { MF.11 } \\
(149,00 \mathrm{~m})\end{array}$ & Dolomito & - & $\begin{array}{l}\text { Poucas espículas de esponjas; poucas calcisferas; poucos } \\
\text { foraminíferos planctônicos; e raros grãos fosfáticos. }\end{array}$ \\
\hline
\end{tabular}

A MF.11, definida pela amostra no calcilutito impuro aos 149,00 m, consiste em material lamoso, inteiramente dolomitizado, decantado sobre porções da plataforma externa (onde organismos bentônicos são excluídos por condições de deficiência em oxigênio; Walter, 2000) distantes da quebra distal de relevo (dada a ausência de sedimentos advindos do talude).

Analogamente, a MF.10, que compreende dois tipos litológicos-texturais na mesma microfácies, também representa a deposição de vasas pelágicas calcárias em porções mais distais da rampa carbonática externa, distante da quebra de talude distal, isenta de expressivos aportes de zonas proximais (dada a predominância de organismos planctônicos), e sob consideráveis condições de anoxia (devido às laminações e ampla piritização).

Define-se então a MF.9, que compreende calcários, texturalmente wackestones bioclásticos, cujo conteúdo microfossilífero relativamente limitado, dominado por uma assembleia planctônica, e associado às estruturas laminares das amostras, evidencia deposição de vasas pelágicas, sob semelhantes condições anóxicas de fundo marinho, em ambiente nerítico profundo da rampa externa. Certamente, às altas proporções de matriz micrítica somam-se a abundância de pitonelídeos e ocorrências de roveacrinídeos que endossam tais condições de baixa energia.

É delimitada a seguir a MF.8, cuja composição é marcada por um espectro de dolomitização ascendentemente decrescente e, texturalmente, é suportada por matriz. Sua feição petrográfica mais distinta é a ampla dissolução trama-seletiva. Nesta microfácies a assembleia é predominantemente planctônica e a dissolução móldica, frequentemente seguida de preenchimento calcítico, sugere ainda uma composição aragonítica das águas em que esses 
organismos se formaram (o que condiz com a abundância de cristais aciculares na matriz lamosa, possivelmente aragoníticos). São também inferidas condições de baixa energia deposicional, em ambiente nerítico profundo sobre a rampa externa (ante a abundância de calcíferas, associada à ocorrência de espículas de esponja).

Ademais, nas amostras 112,95-113,05 m notam-se acúmulos bioclásticos, compartimentados em superfícies de maior compactação química, onde a quebra e deformação dos mesmos parece também indicar um grau de compactação mecânica próprio de rápida perda de sobrepressão (haja vista o contato superior erosivo com a MF.7).

O calcirrudito grosso brechoide da amostra 110,60 m (Figura 8c; MF.7) representa uma inflexão no registro sedimentar subjacente. Como já indicado pela análise macroscópica, esse floatstone calcário denota escorregamentos locais de blocos de wackestones (olistostromas), induzidos por gradientes topográficos mais íngremes, em ambiente nerítico profundo ( $c c$. Koutsoukos, 1989).

E assim, escorregamentos locais de calcilutitos ( $c f$. Schaller et al., 1980) ao longo da quebra distal de relevo da rampa carbonática (Koutsoukos et al., 1993) seriam os processos formadores da MF.7. A assembleia compatível com zonas mais proximais permite identificarlhe os intraclastos.

Segue-se então um pacote de calcário a calcário impuro, bioclástico, matriz-suportado, em que as concentrações terrígenas podem atingir 30\% (MF.6).

Observam-se raros cristais de glauconita nas amostras $106,10 \mathrm{~m}$ e $100,65 \mathrm{~m}$, que marcam episódios de baixas taxas de sedimentação (e onde possivelmente ocorrem hardgrounds, indicando superfícies de máxima inundação), o que pode ter aumentado a concentração de terrígenos original dos sedimentos. Logo, por efeito de compactação química e exportação do material carbonático original, teriam sido intensificados esses teores.

São ainda prevalecentes os grupos fósseis planctônicos nesta microfácies, mas a contribuição de inoceramídeos e equinoides passa a ser consideravelmente maior, o que sugere a deposição de bioclastos em suspensão e bentônicos in situ, ao longo da quebra distal de relevo da rampa carbonática, em ambientes neríticos profundos.
A microfácies seguinte (MF.5) constitui-se de calcários ou calcários dolomíticos a calcários dolomíticos impuros, texturalmente wackestones ou wacke- a packstones bioclásticos, cuja assembleia fossilífera é também dominada por organismos planctônicos, mas que passa a apresentar mais expressivas ocorrências de equinoides (poucos a comuns) e fragmentos de esponja (raros a poucos), embora não sejam atributos faciológicos; além de bivalves (poucos a comuns). Estes últimos possuem concha fina, sugerindo as baixas energias já indicadas pelo espectro textural. Dessa forma, infere-se que a MF.6 represente sedimentação pelágica ao longo da quebra distal de relevo da rampa carbonática externa, em ambientes neríticos profundos.

As amostras petrográficas 76,85 m e 73,10 $\mathrm{m}$, determinam a MF.4, que é formada por calcários impuros a dolomitos calcários impuros, texturalmente wackestones ou wackea packstones bioclásticos. Sua assembleia reúne fragmentos de equinoides muito comuns, submilimétricos a milimétricos, dentre outros microfósseis comumente fragmentados (predominantemente planctônicos).

Assim, à tal assembleia associa-se o pronunciado conteúdo terrígeno, que aponta para uma maior aloctonia nos sedimentos decantados ao longo do talude distal da rampa carbonática externa, em ambientes neríticos profundos (em face da abundância de pitonelídeos, associada às ocorrências de roveacrinídeos).

O intervalo de abrangência da MF.3 coincide com o intervalo amostral interpretado como representante de rápidas mudanças de oxigenação, em razão de sua ausente laminação, juntamente a feições (macroscópicas) sugestivas de bioturbação e considerável assembleia bentônica (embora predominem bioclastos planctônicos).

Seus limites inferiores conformam-se também à superfície de omissão, representada pela amostra 64,90 m (Figura 8), que é interpretada como provável limite do Turoniano inferior.

Mineralogicamente definida como calcário a calcário dolomítico e, texturalmente, como wackestone bioclástico, a MF.3 indica uma sedimentação próximo à quebra distal de relevo da rampa carbonática externa, em ambientes 
neríticos médios a profundos.

Logo delimita-se a microfácies MF.2, que é definida pelas amostras 54,75-58,50 m: calcários impuros a dolomitos calcários impuros; matriz suportados; com assembleia diagnóstica composta por comuns a abundantes equinoides, submilimétricos a milimétricos, e grãos fosfáticos de iguais dimensões, pouco comuns a comuns.

A comum ocorrência de bioclastos milimétricos (notadamente, fragmentos fosfáticos de peixe, equinoides e, mais raramente, ostracode) e de maiores teores de materiais terrígenos (grãos de quartzo detrítico subangulosos e, subordinadamente, palhetas de mica) reflete maior sujeição do ambiente paleodeposicional a aportes da rampa interna ou central.

Entretanto, as texturas deposicionais, parcialmente reconhecíveis, não evidenciam apreciáveis mudanças nas condições energéticas de sedimentação, de maneira que esta microfácies é mais bem caracterizada pela decantação de: organismos planctônicos; bentônicos in situ; além de grãos terrígenos e fragmentos bioclásticos maiores, transportados por correntes das regiões mais proximais para a rampa carbonática externa, acima ou próximo da quebra distal de relevo, em ambientes neríticos rasos a médios.

No topo da seção estudada define-se a microfácies MF.1, que corresponde ao calcirrudito grosso coquinoide (Figura 8a) e que se constitui em dolomito calcário impuro a dolomito, matriz suportado, cuja assembleia diagnóstica abarca: abundantes inoceramídeos silicificados, milimétricos; poucos fragmentos fosfáticos de peixe; e comuns radiolários.

Também se interpreta que sedimentos finos da rampa central sejam transportados por correntes das zonas litorâneas para a rampa externa, onde se depositam, acima do talude distal, em ambiente nerítico raso a médio, em associação às regressões marginais do fim do Turoniano.

\section{CONCLUSÕES}

Diante do empilhamento das microfácies MF.11 a MF.1 (Figura 10), dos processos deposicionais que refletem e, portanto, dos paleoambientes que caracterizam, é possível traçar uma evolução temporal da situação paleoambiental desta sequência, em relação à quebra distal de relevo na rampa carbonática externa (Figura 11).

A cerca de três quartos da profundidade da seção do testemunho estudado (110,60 m), acima de um pacote pelágico de ambientes neríticos profundos (microfácies MF.11-8), a ocorrência de um calcirrudito grosso, brechoide (floatstone calcário), marca notável mudança no regime sedimentar (MF.7): diferentes fases de brechamento e um nítido contato basal erosivo tipificam escorregamento local (fluxo detrítico) de blocos de wackestones (olistostromas) ao longo do talude distal da rampa carbonática; e cujos clastos, de semelhantes litologia e textura, portam uma assembleia compatível com porções mais rasas da mesma rampa carbonática.

Então, a sequência pelágica que se lhe sobrepõe (entre 110,60 m e 64,90 m, aproximadamente; MF.6-4) passa a apresentar: uma contribuição crescentemente maior da fauna bentônica (e de bioclastos de maior granulometria); além de episódios de mais expressiva aloctonia (em função de maiores aportes de terrígenos), em comparação com aquela que lhe antecede; o que condiz com a deposição de bioclastos em suspensão e bentô-nicos in situ, também ao longo da quebra distal de relevo da rampa carbonática, em ambientes neríticos profundos (ratificado pela ocorrência do icnogênero Zoophycos em 70,90 m).

E logo, a sequência pelágica supracitada é interrompida por uma superfície de omissão, que é representada pelo preenchimento gravitacional do Thalassinoides na profundidade 64,90 m (Figura 10).

A esta superfície se atribui uma acentuada seção condensada, que se registra nas curvas eustáticas, e que corresponde precisamente ao limite do Turoniano inferior.

Tal marco estratigráfico associa-se à desaceleração das taxas deposicionais já próximas ao Turoniano médio, que resulta deste evento de inundação máxima, e que traça o fim da transgressão marinha e marca o limite das sequências: trato de sistemas transgressivo e trato de sistemas de mar alto.

Posteriormente, segue-se um pacote pelágico, mais nitidamente bioturbado (Thalassinoides reconhecível em 59,40 m), no qual se identifica um nível de wackestone bioclástico, calcário a calcário dolomítico (MF.3), em que a ausente laminação e a assembleia bentônica associada sugerem rápidas mudanças de oxigenação. 

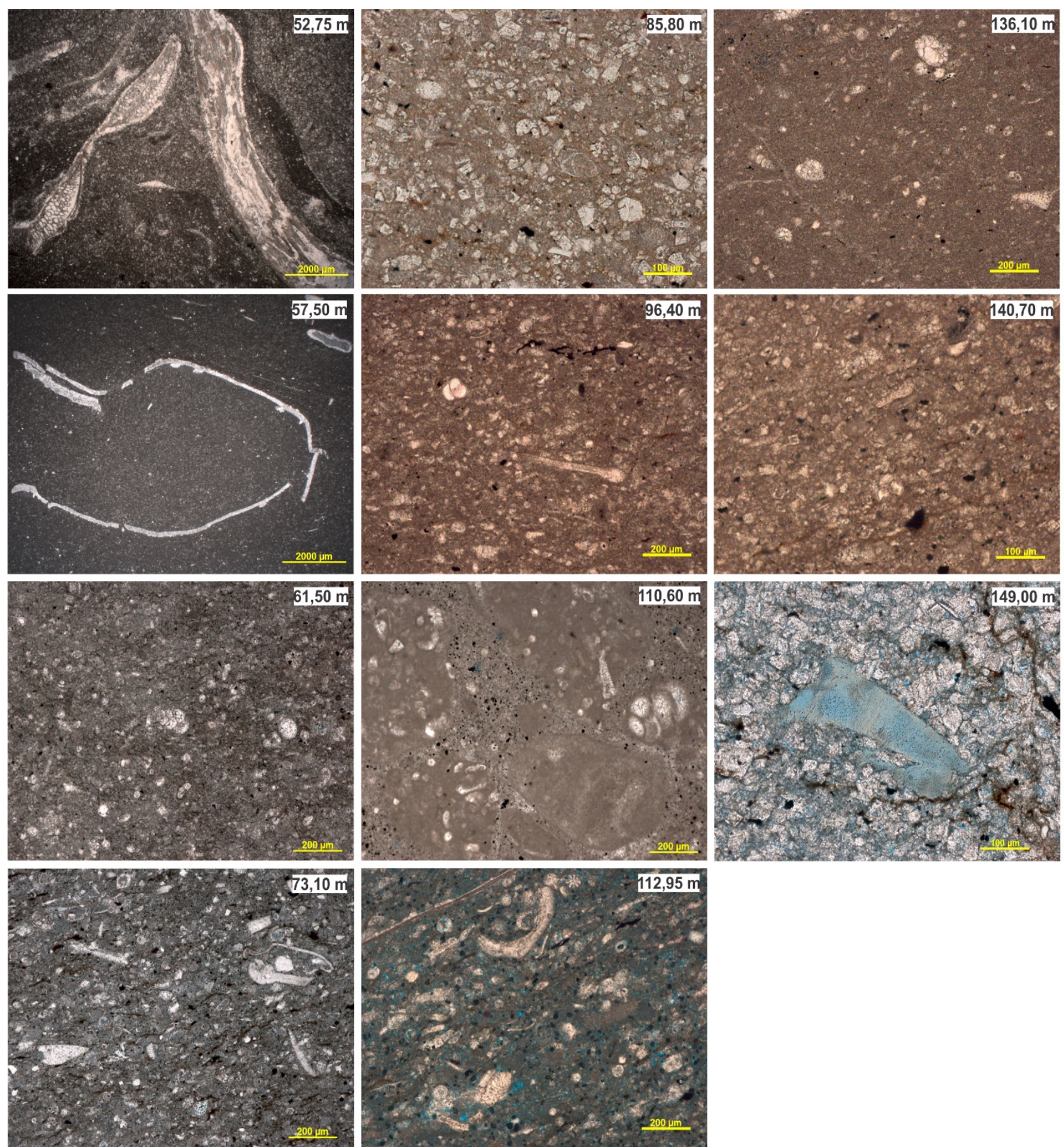

Figura 10 - Fotomicrografias representativas das onze microfácies que se distribuem na sucessão sedimentar do testemunho estudado e respectivas profundidades amostrais.

De fato, a partir de então, não mais se observam claras estruturas de laminação e, nos calcários (a dolomitos calcários) impuros, suportados por matriz que se superpõem (MF.2), passam a se registrar comumente fragmentos milimétricos de equinoides e (fosfáticos) de peixes - o que demonstra uma maior sujeição do ambiente paleodeposicional a aportes da rampa interna ou central, embora as texturas ainda sejam concordantes com processos de decantação acima ou próximo da quebra distal de relevo da rampa, em ambientes neríticos rasos a médios. A esse pacote se sucedem dolomitos a dolomitos

calcários impuros, matriz suportados (calcirruditos grossos, coquinoides; MF.1), cuja abundância em inoceramídeos milimétricos silicificados, associada a grãos esqueletais fosfáticos de iguais dimensões, assevera o transporte por correntes das zonas litorâneas para a rampa externa - onde se depositam lama pelágica e fragmentos bioclásticos, acima do talude distal, em ambiente nerítico raso a médio.

Este pulso de sedimentação rudítica responde provavelmente às regressões marginais, consecutivas ao pico deposicional do fim do Turoniano. 


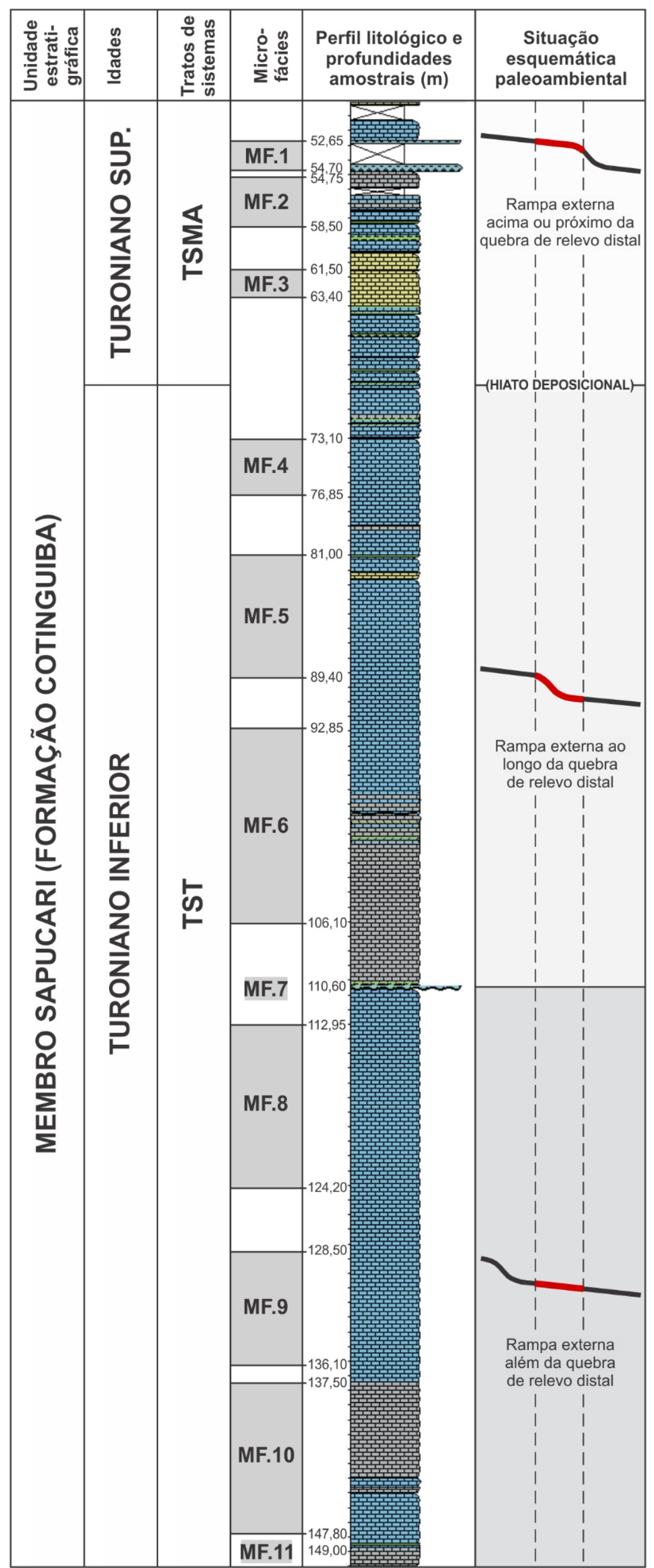

Figura 11 - Distribuição das microfácies na sucessão sedimentar (v. legenda litológica no perfil da Figura 7). 
Dessa forma, as taxas de aporte sedimentar (e de produtividade carbonática da rampa) eram ascendentes e superiores à subida do nível relativo do mar (em contínua desaceleração, por controle eustático), de modo que a regressão nas áreas marginais da sub-bacia de Sergipe, posteriormente registrada, pode ser atribuída a um evento de regressão normal.

Portanto, conclui-se que: a presente seção em testemunho da Formação Cotinguiba representa a progradação que modela a rampa carbonática, por fluxos gravitacionais ao longo do talude; na qual figuram depósitos pelágicos distantes da quebra distal de relevo, ao longo da mesma (ambos interpretados como trato de sistemas transgressivo, de idade turoniana inferior) e, $a$ posteriori, acima da referida quebra, aos quais se confere idade turoniana superior (interpretados como trato de sistemas de mar alto), e que culminam com aportes sedimentares de zonas proximais (representativos da regressão normal nas áreas marginais da Bacia).

Assim, para que se consolidem ou se retifiquem tais premissas estratigráficas (sobretudo com respeito à superfície de omissão representada pelo Thalassinoides da amostra $64,90 \mathrm{~m}$ ), os métodos analíticos aqui presentes devem ser complementados por estudos ciclo estratigráficos (com base em índices de resíduos insolúveis ou carbono orgânico total, e.g.) e bioestratigráficos (baseados em foraminíferos, e.g.).

\section{AGRADECIMENTOS}

Os autores são gratos ao projeto COPPETEC IGEO 15.981 (SACL - Sergipe Alagoas Carbonate Laboratory) pelo financiamento da pesquisa e pela infraestrutura laboratorial, provida pelo Laboratório de Geologia Sedimentar (LAGESED - UFRJ). Foi igualmente valiosa a contribuição do geólogo Roberto Pereira (UFRJ), que concedeu os dados bioestratigráficos aplicados ao presente estudo microfaciológico.

\section{REFERÊNCIAS}

ANTUNES, R.L. Nanofósseis calcários e sua bioestratigrafia no Cretáceo da Margem Continental Brasileira. Bacias do Ceará e Potiguar. Rio de Janeiro, 1998. 193. Tese (Doutorado). Universidade Federal Rio de Janeiro.

BARREIRO, C.B.; MIZUSAKI, A.M.P.; GARCIA A.J.V. Análise da seção de transição pré-rifte/rifte (Formações Serraria e Barra de Itiúba) da Bacia Sergipe-Alagoas. In: CONGRESSO BRASILEIRO DE P\&D EM PETRÓLEO E GÁS, 2, 2003, Rio de Janeiro. Anais...Rio de Janeiro: Universidade Federal Rio de Janeiro, 2003.

BERTHOU, P.Y. \& BENGTSON, P. Stratigraphic correlation by microfácies of the Cenomanian-Coniacian of the Sergipe Basin, Brazil. Fossils and Strata, v. 21, p. 1-88, 1988.

DNIT, DEPARTAMENTO NACIONAL DE INFRAESTRUTURA DE TRANSPORTES. ATLAS MULTIMODAL. Disponível em: http://www.dnit.gov.br/ download/mapas-multimodais/atlas-multimodal/atlas.pdf. Acesso em: 13/10/2015. 2011.

CAMPOS NETO, O.P.; SOUZA LIMA, W.; CRUZ, F.E.G. Bacia de Sergipe Alagoas. Boletim de Geociências da Petrobras, Rio de Janeiro, v. 15, n. 2, p. 405-415, 2007.

CHAMBERLAIN, C.K. Recognition of trace fossils in cores. In: BASAN, P.B. (Ed.), Trace fossil concepts. Tulsa, Oklahoma: Society of Economic Paleontologists and Mineralogists, p. 133-183, 1978.

DUNHAM, R.J. Classification of Carbonate Rocks Acording to Depositional Texture. AAPG Memoir, p. 108-121, 1962.

EMBRY, A.F. \& KLOVAN, J.E. A Late Devonian reef tract on northeastern Banks Island, N.W.T. Bulletin of Canadian Petroleum Geology, v. 19, p. 730-781, 1971.

FEIJÓ, F.J. Bácias de Sergipe e Alagoas. Boletim de Geociências da Petrobrás, v. 8, p. 149-161, 1995.

FLÜGEL, E. Microfácies of Carbonate Rocks. 2. ed. Heidelberg: Springer. 1006 p., 2010.

FOLK, R.L. Spectral subdivision of limestone types. - In: HAM, W.E. (ed.): Classification of carbonate rocks. A symposium. - Amer. Ass. Petrol. Geol. Mem., v. 1, p. 62-84, 1962.
GIANNINI, P.C.F. Depósitos e rochas sedimentares. In: TEIXEIRA, W.; FAIRCHILD, T.R.; TOLEDO, M.C.; TAIOLI, F. ed. Decifrando a Terra. São Paulo, Oficina de Textos. p. 301, 2000.

HAQ, B.U.; HARDENBOL, J.; VAIL, P.R. Chronology of fluctuating sea levels since the Triassic. Science, v. 235, n. 4793, 1156-1167, 1987.

KOUTSOUKOS, E.A.M.; MELLO, M.R.; AZAMBUJA FILHO, N.C. Micropalaeontological and geochemical evidence of mid-Cretaceous dysoxicanoxic environments in the Sergipe Basin, northeastern Brazil. In: Modern and Ancient Continental Shelf Anoxia (Eds TYSON, R.V. \& PEARSON, T.H.). Geological Society of London Special Publication, v. 58, p. 427-447, 1991.

KOUTSOUKOS, E.A.M.; DESTRO, N.; AZAMBUJO FILHO, N.C.; SPADINI, A.R. Upper Aptian-Lower Coniacian Carbonate Sequences in the Sergipe Basin, Northeastern Brasil. In: Cretaceous Carbonate Platforms (Edited by SIMO, T.; SCOTT, R.W.; MASSE, J.P.). American Association of Petroleum Geologists Memoir, n. 56, p. 127-144, 1993.

MOHRIAK, W.U. Bacias Sedimentares da Margem continental Brasileira. In: BIZZI, L.A.; SCHOBBENHAUS, C.; VIDOTTI, R.M.; GONÇALVES, J.H. Geologia, Tectônica e Recursos Minerais do Brasil: CPRM. Serviço Geológico do Brasil, p. 139-142, 2003.

MOORE, J.r.T.C., van Andel, T.J.H.; Sansetta, C.; Pisias, N. Cenozoic hiatuses in pelagic sediments. Micropaleontology, v. 24, p. 113-138, 1978.

PEREIRA, M.J. Sequências deposicionais de $2^{\mathrm{a}} / 3^{\mathrm{a}}$ ordens $(50$ a 2,0 Ma) e tectonoestratigrafia no Cretáceo de cinco bacias marginais do Brasil. Comparações com outras áreas do globo e implicações geodinâmicas. Universidade Federal do Rio Grande do Sul, 2 volumes, 295 pp. 1994.

PETTIJOHN, F.J. Sediment.ary rocks. 2.ed. Nova Iorque: Harper \& Row. 718 p. Il. 1957.

SANTOS, P.R.S. Palinoestratigrafia do Turoniano na área de Laranjeiras, Bacia de Sergipe-Alagoas: inferências paleoambientais e paleoclimáticas. Boletim de Geociências 
da Petrobras, Rio de Janeiro, v. 16, n. 1, p.121-138, 2007.

SCHALLER, H.; DELLA FÁVERA, I.C.; TIBANA, P. Roteiro geológico da Bacia de Sergipe-Alagoas. Rio de Janeiro, Petrobrás, (Relatório Interno), 1980

SCHOLLE, P.A. \& ULMER-SCHOLLE, D.S. A Color Guide to the Petrography of Carbonate Rocks, AAPG Memoir v. 77, 474 p., 2003.

SLITER, W.V. Cretaceous planktic foraminiferal biostratigraphy of the Calera limestone, northern California, USA. Journal of Foraminiferal Research, v. 29, p. 318-329, 1999.

SOUZA-LIMA, W.; ANDRADE, E.J.; BENGTSON, P.; GALM, P.C. A Bacia de Sergipe-Alagoas: Evolução geológica, estratigráfica e conteúdo fóssil. Aracaju. Fundação Paleontológica Phoenix, 34 p. Edição especial 1, 2002.
VON STACKELBERG, U. Fazies verteilung in sedimenten Indisch-Pakistanischen Kontinentalrandes (arabisches Meer): "Meteor" Forsch. -Ergebn., v. E9, p. 1-106, 1972.

WALTER, S. Palaeoenvironmental analysis of the upper Cenomanian and lower Turonian limestone beds in the Sergipe Basin, northeastern Brazil, based on microfacies analysis, micropalaeontology, and stable isotopes. 2000. 71p. Tese (Doutorado). Universidade de Heidelberg, Mannheim.
Submetido em 17 de maio de 2017 Aceito em 3 de maio de 2019 